\title{
A comparison of GPS solutions for strain and SKS fast directions: Implications for modes of shear in the mantle of a plate boundary zone
}

\author{
Journal Article \\ Author(s): \\ Houlié, Nicolas; Stern, Tim \\ Publication date: \\ 2012-09 \\ Permanent link: \\ https://doi.org/10.3929/ethz-a-009935856 \\ Rights / license: \\ In Copyright - Non-Commercial Use Permitted \\ Originally published in: \\ Earth and Planetary Science Letters 345-348, https://doi.org/10.1016/j.epsl.2012.06.029
}




\title{
A comparison of GPS solutions for strain and
}

\section{SKS fast directions: implications for modes of}

\section{shear in the mantle of a plate boundary zone}

\author{
N. Houlié ${ }^{1}$ and T. Stern ${ }^{2}$ \\ ${ }^{1}$ School of Earth and Environment, University of Leeds, Leeds, UK. Email: \\ n.houlie@leeds.ac.uk, Tel.: +44113343 6620, Fax: +441133435259 \\ ${ }^{2}$ University of Victoria, Wellington, New Zealand
}

\begin{abstract}
The strain rate and vertical velocity fields for New Zealand are computed using GPS data from GEONET (NZ) collected during the past decade. Two domains for shear in the mantle are inferred by comparing the principal shortening direction with the fast direction of shear wave splitting. Beneath the central-southern part of the South Island the strains are low and it's unclear if irrotational strain is taking place or if the splitting here is dominated by anisotropy in the asthenosphere. In contrast, data for the central and northern South Island suggest simple shear is dominant and distributed over a zone $200 \mathrm{~km}$ wide. An analysis of the major strike-slip faults confirms that the strike of the major South Island fault systems makes a $60 \pm 15$ degree angle with the shortening direction. A map of the vertical component of GEONET GPS velocities shows regions of surface uplift $>5 \mathrm{~mm} / \mathrm{y}$
\end{abstract}


in both the central South and North Islands. While the pattern of uplift in central South Island is consistent with known geology, the rate of uplift in the central North Island is an order of magnitude higher than the geological rate estimated on a my time scale.

\section{$1 \quad 1$ Introduction}

2 How and where strain is accommodated in the continental mantle lithosphere 3 remains unclear. In particular, how is strain distributed in the mantle beneath 4 transform faults? And if is distributed, how does the crust and mantle deform 5 together [1]? Central New Zealand is a favourable locality to examine these 6 questions as it straddles the plate boundary between the Pacific and Aus7 tralian plates, and the boundary is characterized by a $\sim 200 \mathrm{~km}$-wide zone of 8 seismicity, faulting and shear wave splitting [2,3,4].

9 In the past two decades shear wave splitting has become an important, albeit

controversial, tool to examine deformation in the lithosphere and asthenosphere [5,67]. There is debate about the role of fluid-filled cracks versus aligned minerals as the cause of anisotropy in the crust, but within the mantle lattice preferred orientation (LPO) is a widely accepted cause of anisotropy [8,9].

One aspect that can be difficult to resolve is the relative role of flow in the asthenosphere versus strain in the overlying lithosphere in SKS splitting[4]. Shear wave splitting is manifest in two ways: the amplitude of the difference in shear waves travelling through the earth $(d t)$ with different polarisations 
18

19

(transverse and radial components), and the azimuth of the ray paths that give the largest split, which is interpreted as the direction of the mantle extension. This azimuth is called the fast direction. Interpretation of mantle anisotropy is complex but $d t$ can be related to the thickness of the mantle layer that is deformed and the intrinsic anisotropy of minerals that make up mantle rocks. Traditionally, the interpretation of the extension (fast) direction was that it was parallel or sub parallel to the direction of shear in the lithosphere or flow in the asthenosphere [6]. In practice the fast direction can be influenced by a range of factors including the magnitude of finite strain, the shear strain rate and the amount and pressure of water [10].

In New Zealand analysis of SKS splitting has stimulated interpretations in terms of both asthenospheric flow and shear in the lithospheric mantle $11,3,12$. Pn anisotropy, which samples only the top of the mantle lid, is also observed and is consistent with the SKS splitting results if most of the anisotropy is confined to a lid of mantle lithosphere some $150 \mathrm{~km}$ thick that is being sheared [13]14]. However, the consistency of SKS splitting amplitudes and fast directions throughout New Zealand hints at the possibility that some of the anisotropy may be created in the asthenosphere rather than all being due to shearing of the mantle lid [15].

Because New Zealand is a continental region surrounded by oceans the plate tectonic history is well known and the total amount of offset on its major faults can be estimated [16]. There is, therefore, an opportunity to calibrate total 
offset due to shear with the width of the sheared region and with the direction and amplitude of shear wave splitting. Previous attempts to understand strain in the mantle beneath the South Island have examined the relationship of the orientation of the fast S-wave polarization from SKS splitting to the direction of the major crustal faults, assuming that the strike of the faults is a proxy for direction of shear strain in the mantle [3,14,4]. Here we take a different approach by considering the maximal strain rate component $\left(\dot{\varepsilon}_{1}\right)$ direction, from GPS data, as a proxy for the direction of shear strain in the mantle. An underlying assumption is that a sample of $10 \mathrm{y}$ of GPS data provides strain and strain rates that are also applicable to the My time scale.

In New Zealand, shear-wave splitting results show a consistent pattern of splitting amplitudes and directions [17,4]. In addition, a continuous GPS network has been set up (GEONET) which has now given a decade of data from which reliable strain rate components can be mapped on a continent-wide scale [18]. In this paper, we use a new epoch of data (1999-2009) from the GEONET GPS array to examine both horizontal and vertical motion rates. Uncertainties for the vertical velocities are $\pm 50 \%$ and we only present a map (fig.2) with minimal discussion. Horizontal velocities (fig. 3)are better resolved ( $\pm 5 \%$ ), and we map the relationship of principal geodetic compression axis to SKS splitting directions. 


\section{Datasets}

${ }_{61}$ With an average spacing larger than $40 \mathrm{~km}$, the GEONET (NZ) network is

62

63

64

65

66

67

68

69

70

71

72

73

74

75

76

77

78

79

80

similar in design to other GPS networks such as Plate Boundary Observatory (PBO) [19,20], PANGA[21], BARD [22|23|24] or EUropean REference Frame (EUREF, 25]) networks. GEONET and the other networks listed above are designed to describe continental scale deformation but cannot describe the sharp velocity gradients related to shallow fault systems or upper crust deformation.

We processed the 30 s sampling rate data collected by GEONET using the GPS processing package GAMIT 10.4 [26]. The daily solutions were combined with GPS solutions for North America spanning a longer period (1994-2009) [24]. Solutions computed for New Zealand include sites already processed in the International Terrestrial Reference Frame 2000 (ITRF2000) [27]) by including 5 IGS sites: AUCK, DUND, GOLD and YSSK and GUAM. The network solutions are then referenced in the ITRF without increasing the computational time. This approach, already used for networks far (>500 km) from longestablished GPS permanent sites [28], allowed the solutions to be anchored in the global network. The adjustment of daily solutions has been completed with the package GLOBK/GLORG [26]. All the ITRF velocities are displayed in Table 1. For convenience, we plot the velocity field with respect to the site New Plymouth (NPLY) on Figure 1 
The geodetic (ground-based geodetic surveys) dataset has been collected from 1875 to 1970 s using optical instrumentation [29,2]. This dataset was used to provide shear strain values and orientations of the compression axis. By using uncertainties of shear strain rate components $\left(\gamma_{1}\right.$ and $\left.\gamma_{2}\right)$, we estimate that the shear strain rate $(\gamma)$ uncertainties for the geodetic dataset are high (50\%(or $10^{-7}$ strain) or more). The uncertainties for the orientations of the strain rate, however, are more accurate (usually uncertainties on angles are less than 10 degrees [2]).

We compute (Figure 3) the strain rate components (compressional, rotational and shear) for the GPS velocity field using the SSPX package [30]. The strain rate maps have been inverted on a grid using a nearest-neighbor interpolation (6 neighbors, maximal distance $200 \mathrm{~km}$ and a grid size of $50 \mathrm{~km}$ ). The insignificant strain values (where the strain rates computed are smaller than their uncertainty) have been computed following this same method [31. As the site GUNR had only been installed for 9 months at the time of the analysis, it was removed from all the strain rate computations. All the components of strain rate are computed and plotted on Figure 4.

The amplitudes of the geodetic shear strain rates reported by [2] based on a time line of 100 yrs are larger (2 to $410^{-7} / y r$ ) than that for the GPS data that span 10 years. Although the uncertainties on the geodetic measurements are large (50\% or more for strain rate amplitudes), we explain the high shear strain rates from the 100 yr span geodetic network by the fact that strain rate 
might be distributed along shorter baselines. i.e. $2-10 \mathrm{~km}$ base lines rather than $40 \mathrm{~km}$ baselines for the GPS data. The survey would then be able to better localize strain rate than a GPS permanent network. A similar effect has been discussed in northern California where gradients of velocities larger than expected could be interpreted in terms of larger local values of shear strain rates[24].

We compare this dataset of surface velocities with the shear wave splitting collected over the past 15 years in New Zealand. Data on SKS splitting shows a consistent pattern of roughly trench parallel fast directions over most of the country [32,11,33,34,35,36,4].

\section{Analysis}

\subsection{GPS vs Geodetic}

The GPS data solutions show that across the central South Island, at least 20 $\mathrm{mm} / \mathrm{yr}$ of differential lateral motion (N225) must be accommodated. If such a strain were accommodated across the whole width $(160 \mathrm{~km})$ of the island, the maximum shear strain rate value would be $1.2510^{-7} \mathrm{yr}^{-1}$. This is a similar shear strain rate to that proposed by [37] in the Marlborough area or by [38] for the whole of New Zealand. However, the strain rate values proposed by [2] range from 3.1 to $6.810^{-7} \mathrm{yr}^{-1}$. Therefore, if we honour both Walcott's finding 
and the GPS data, then most of the strain is accommodated across a zone some 30 to $70 \mathrm{~km}$ wide. This width for distributed strain is consistent with that predicted by a model based on GPS data in the central South Island [12] geological observations [39] and previous analyses of campaign GPS data [40].

\subsection{GPS solution for Vertical motion}

A solution for vertical GPS displacements over the past 10 years (fig. 2) shows broad scale vertical movements of New Zealand. These GEONET data are supplemented by a line of GPS receivers across the mid South Island that were put in for the purpose of measuring the rate of vertical surface uplift across the Alpine Fault [41,42]. Smoothing is done by bi-cubic interpolation [43] with a point every $\sim 0.5$ degree so wavelengths less than $100 \mathrm{~km}$ will not be faithfully displayed (Figure 22). We reference the absolute level of this surface uplift map by adopting a finding from recent micro-paleontological studies in the northern Marlborough Sounds that show a $0.8 \pm 0.25 \mathrm{~mm} / \mathrm{y}$ rate of subsidence in the past 4 kyr [44]. We adjusted all stations to honour this data point as it's based on a short time interval and it's from a part of the coast where it's obvious since the earliest geological studies that present day subsidence is occurring [45]. Rates of surface vertical movement of up to $5-8 \mathrm{~mm} / \mathrm{y}$ are predicted for the Central Volcanic Region of the North Island and the central Southern Alps. The latter Southern Alps observation correlates well with the isostatic vertical strain rate field we can compute from horizontal strain rate components and 
(Figure 4). A caveat on this map is that the errors are $\pm 2 \mathrm{~mm} / \mathrm{y}$, meaning that much of the signal does not rise above the uncertainty. Furthermore, the spacing of stations is such that many areas of the country, or processes, are aliased and not reliably sampled. For example, the narrow $(\sim 50 \mathrm{~km})$ axial ranges of the North Island are not sampled and rates of uplift here are $\sim$ $1-3 \mathrm{~mm} / \mathrm{y}$ [46]. Nevertheless, the results are broadly consistent with what is known from other local geological observations. For example, the central North Island shows a broad uplift rate of about $5 \mathrm{~mm} / \mathrm{y}$, based largely on stations Tauranga and Taupo which show values of 3.7 and $6.8 \mathrm{~mm} / \mathrm{y}$ respectively (Figure 3). The uplift pattern of the central North Island is consistent with the longer $(5 \mathrm{My})$ term rock uplift pattern from mudstone porosity data and based on samples points just outside the CVR [47]. However, the short-term rate from vertical GPS is about 10 times greater than the long-term, geological uplift rate. This difference could be explained by the different space and time sampling frequency, or the present day uplift could be a temporary phenomena similar to one of the uplift events observed at Yellowstone caldera in the past 100 yrs [48]. If the latter, then the vertical uplift velocities for this part of the country should be closely monitored. Positive uplift rates down the south-western coast of North Island are consistent with offshore islands just north of Wellington with wave-cut platforms now at $40 \mathrm{~m}$ above sea level [49] and recent uplift in the Wellington city region [50]. In the South Island the most extensive area of uplift is the Southern Alps with the rapidly uplifting Kaikoura Mountains [51] not showing up on this map because there are no 
${ }_{184} \quad V_{u p}=\dot{\varepsilon_{3}} D \frac{\left(\rho_{m}-\rho_{c}\right)}{\rho_{m}}$

GPS stations near by. Surface uplift on and east of the Alpine fault is shown clearly as this anomaly is well defined by the focussed data from a profile of 14 GPS stations across the Alps [42]. Note that the area of uplift is shown to extend across the western side of the Alpine Fault. This is likely to be an artefact of the smoothing used to present the sparsely and unevenly distributed data.

We compare the observed uplift map with the uplift computed from the combination of the vertical strain rate map assuming that the crust is incompressible (Figure 51):

$$
\dot{\varepsilon_{3}}=-\left(\dot{\varepsilon_{2}}+\dot{\varepsilon_{1}}\right)
$$

Assuming the sum of the uplift rate $V$ and and motion of the root $V_{r}$ are related to the compression of New Zealand crust, we compute the motion of the base of the crust of constant thickness $D=40 \mathrm{~km}$ (Figure 5 ).

$$
\left(V-V_{r}\right)=\dot{\varepsilon_{3}} D
$$

We compute the uplift rate $\left(V_{u p}\right)$ expected if New Zealand crust is close to the isostatic equilibrium. We assume the crust is of constant thickness $D$ and the ratio $\frac{\left(\rho_{m}-\rho_{c}\right)}{\rho_{m}}=1 / 6.6$, where $\rho_{m}$ and $\rho_{c}$ are respectively the mantle and crustal densities): 
We show the distribution of $V_{u p}$ on Figure 5. We conclude that except in the area of the Alpine fault and in the Central Volcanic region of North Island, the crust is close to the isostatic equilibrium (Figure 5 ).

\subsection{Vertical motion and mantle dynamics}

Although the central North and South islands have similar uplift rates over similar areas (Figure 2), the processes responsible for uplift are distinctly different. In the central South Island crustal thickening has occurred for at least $7 \mathrm{My}$ [2,52] and it's of the order of $60 \%$ compared to that at the coasts [13]. Uplift here can be explained by simple crustal thickening, although uniform thickening of the mantle beneath the Southern Alps [53] has probably served to slow the surface uplift. In stark contrast the central North Island has been subjected to extension and crustal thinning for the past $5 \mathrm{My}$ [54,55]. Seismological evidence [56,57] shows anomalous slow seismic wave-speeds and high attenuation in the upper mantle of the central North Island. Heat output via the active geothermal systems is at a rate about 12 times greater than normal for continental regions [58/59]. Thus while uplift of the central South Island is largely mechanical, uplift of central North island is seen to be more of a thermal process linked to both back-arc spreading, loss of mantle lithosphere and enhanced buoyancy of the asthenosphere [47]. 


\subsection{Present day shortening directions vs $S$-wave fast axes}

For the case of simple shear, deformation in the mantle is a function of the angle $\theta$ that is the angle between the SKS fast direction and the direction of shear [3]. In previous studies in the South Island the strike azimuth of the Alpine Fault has been taken as the shear direction in the mantle. Here we redefine $\theta$ to be the angle between the perpendicular of the compression axis as defined by the GPS solutions and the fast direction for SKS splitting (Figure 6). On this basis there are 3 distinct zones of different $\theta$ within New Zealand (Figure 8). Zone 1 in central and northern North Island shows little organisation because here SKS splitting and mantle flow is influenced by magmatic processes linked to complexities of back-arc spreading [17]. In the southern and central South Island there is a zone 3 where $\theta \sim 3 \pm 11$ degree and which is characterised by low strain values. Finally, there is the central zone 2 from mid south Island to the south of the North Island where $\theta$ increases on average up to $28 \pm 9$ degrees (with a highest value close to 50 degrees) (Figure 10).

As [7] did for California, we argue that the similarity directions of the GPS derived axes of compression and extension through the mantle and indicate a close coupling between strain in the mantle and in the crust. This inference is largely based on the observation that the GPS strain directions vary smoothly over $100 \mathrm{~km}$ or more. A similar conclusion about a coupling between crust and mantle, for at least the Marlborough faults region, was reached on the basis 
of GPS and fault slip data[60]. Thus, instead of taking the strike directions of major faults as being indicative of the shear direction in the mantle, we propose that the GPS axis of extension is a better proxy for the orientation of mantle shear. Moreover, we assume that the present-day direction pertains to the past 5 my or so when at least half the strike-slip motion and shortening occurred [12]. At this stage we consider just two end-member models for strain in the mantle; simple shear and pure shear. Each mode carries with it implications for the relationship between strain direction and the fast direction of SKS splitting (Figure 8). For pure shear the direction of principal extension does not rotate with increasing finite strain and is expected to define the fast axis polarization direction for SKS splitting. In contrast, for simple shear the relationship between the angle of the principal extension direction $(\theta)$, the total displacement $(d)$ and the width of the deforming zone $(w)$ is given by [3]:

$$
\tan (2 \theta)=2 w / d
$$

The $28 \pm 9$ degree angle between the SKS fast direction and the GPS axis of extension in zone 2 implies a finite amount of simple shear. From equation 1 , as shear, or displacement $\mathrm{d}$ increases to infinite amounts, $\theta$ approaches zero. Taking $\theta=28$ degrees, the value of $d=850 \mathrm{~km} \mathrm{[16]} \mathrm{then} w$ is predicted to be $\sim$ $200 \mathrm{~km}$, which is about the width of the northern South Island. Interpetation of zone 3 is not straightforward as there are several ways to interpret the low 
angle of $\theta$. Either the strain here is much higher than further north, which seems unlikely, or there is a different dominant mode of strain. For example, with pure shear the $\theta$ angle remains close to zero (Figure 9). If there is some combination of pure and simple shear the angle can also be close to zero [61.A third possibility is that as the strain rates are low here, and anisotropy due to shear in the asthensophere dominates 62. This result is based on an analysis of local splitting events showing that the dominant SKS splitting must be from depths $>100 \mathrm{~km}$ deep.

\subsection{Fault strike vs GPS}

Our above analysis of geodetic extension directions versus fast polarization directions for S-waves has provided insight to mantle processes. If, on the other hand, we want to learn about stress and strain in the crust we need to examine the relationship between shortening directions and strike directions of major strike-slip geological faults. In this regard, we measure the angle (alpha) between the strike of the faults and the principal shortening axes of the geodetic strain field (Figure 8). The angle alpha shows values of 60-80 degrees for most of strike slip faults of the Marlborough and the central Alpine Fault, 30 degrees for faults elsewhere in the South Island and 18-30 degrees in the Wellington region (Figure 8). The high alpha angles of $\sim 60$ degrees for Marlborough faults and the Alpine fault of compression are compatible with the analysis of past geodetic surveys (shortening axis) [2] and recent seismologi- 
cal studies of maximum compressive stress $\left(\sigma_{H}\right)$ completed in the area of the central and northern South Island [63,64,65]. Thus stress and strain axes are aligned suggesting the material is isotropic. A 60 degree angle for alpha is also similar to the situation on San Andreas fault in northern California [66] who argue that optimal orientation for $\sigma_{H}$ for fault that is strong as its surrounding rock is 30 degrees, and that a 80 degree angle is appropriate for a weak fault embedded in strong rock. Our interpretation of the 60 degree alpha angle for the Marlborough and Alpine faults is that friction has been reduced because of enhanced fluid pressure as inferred from geophysical surveys [67,68].

\section{Discussion}

In this study we have presented GPS vertical and horizontal solutions for the New Zealand land mass based on 10 years of data. The horizontal data gives us a strain field similar to that published elsewhere [18. The vertical solution for the whole country has not been computed before and the map we produce is the first such attempt. In 10 years time a better solution will be achievable. Nevertheless, the results of the surface uplift map are consistent with what we know from geological observations. We do, however, highlight the surprisingly high rate of uplift in the central North Island which, if real, should be closely monitored. We present an analysis of the angle between GPSderived compression axes directions with SKS directions $(\theta)$. This analysis 
gives us new insight into mantle deformation in the sense that this definition of theta allows us to partition New Zealand into 3 domains. The most southern domain shows $\theta \sim 0$ and is interpreted as zone of both simple and pure shear with perhaps the dominant of the latter in the past 5 my. Strain rates are, however, low here and other interpretations of a low theta value are possible. The middle of New Zealand, including the Marlborough faults region, has $\theta \sim 28$ degrees and here we suggest a mode of simple shear over a zone $\sim$ $200 \mathrm{~km}$ wide. This interpretation differs slightly from previous ones 69, 14 in that the interpretations of the southern and middle domains, in terms of simple and pure shear, were reversed. The different point of view comes about by hypothesising that the GPS derived extension direction is a proxy for the present day shear in the mantle lithosphere. Finally, we compare the strikes of faults versus the orientations of compression axis and conclude that because of the dominant high angles, most of the strike slip faults of central New Zealand, including the Alpine fault, are of low friction possibly due to high fluid pressures. 


\section{Acknowledgements}

This work has been funded by the New Zealand Royal Society - International Mobility Fund. We thank G. Houseman and C. Green for their comments

\section{References}

[1] W. Thatcher, Microplate versus continuum descriptions of active tectonic deformation, J. Geophys. Res. 100 (1995) 3885-3894.

[2] R. Walcott, The kinematics of the plate boundary zone through new zealand: a comparison of short- and long- term deformations, Geophys. J.R. astr. Soc. 79 (1984) 613-633.

[3] P. Molnar, H. Anderson, E. Etienne Audoine, D. Eberhart-Phillips, K. R. Gledhill, E. R. Klosko, T. V. McEvilly, D. Okaya, M. Savage, T. Stern, F. Wu, Continuous Deformation Versus Faulting Through the Continental Lithosphere of New Zealand, Science 286 (516).

[4] M. Savage, M. Duclos, K. Marson-Pidgeon, Seismic anisotropy in south island, new zealand, in: D. Okaya, T. Stern, F. Davey (Eds.), A continental Plate Boundary: tectonics at South Island, New Zealand Geophysical Monograph Series 175, American Geophysical Union, 2007, pp. 95-116.

[5] N. M. Ribe, On the relation between seismic anisotropy and finite strain, J. Geophys. Res. 97 (1992) 8737-8747. 
[6] M. K. Savage, Seismic anisotropy and mantle deformation: what have we learned from shear wave splitting studies, Rev. of Geophys. 37 (1999) 65-106.

[7] J. Polet, H. Kanamori, Anisotropy beneat California: shear wave splitting measurements using a dense broadband array, Geophys. J. Int. 149 (2002) 313327.

[8] P. Silver, W. Winston Chan, Shear wave Splitting and Subcontinental Mantle Deformation, J. Geophys. Res. 96 (B10) (1991) 16,429-16,454.

[9] P. G. Silver, Seismic anisotropy beneath the continents: probing the depths of geology, Ann. Rev.Earth Planet. Sci. 24 (1996) 385-432.

[10] H. Jung, S. Karato, Water-induced fabric transitions in olivine, Science 293 (2001) 1460-1463.

[11] K. Marson-Pidgeon, M. Savage, K. Gledhill, G. Stuart, Seismic anisotropy beneath the lower half of the North Island, New Zealand, J. Geophys. Res. $104(1999)$ 20,277-220,286.

[12] M. Moore, P. England, B. Parsons, Relation between surface velocity field and shear wave splitting in the south island of new zealand, J. Geophys. Res. 107 (B9).

[13] M. Scherwath, T. Stern, A. Melhusih, P. Molnar, Pn anisotropy and distributed upper mantle deformation associated with a continental transform fault, Geophys. Res. Lett. 29 (8).

[14] G. Baldock, T. T. Stern, Width of mantle deformation across a continental transform: evidence from upper mantle (Pn) seismic anisotropy measurements, 
Geology 33 (2005) 741-744.

[15] M. Savage, A. Tommasi, S. Ellis, J. Chery, Modeling Strain and Anisotropy Along the Alpine Fault, South Island, New Zealand, in: D. Okaya, T. Stern, F. Davey (Eds.), A continental Plate Boundary: tectonics at South Island, New Zealand Geophysical Monograph Series 175, American Geophysical Union, 2007, pp. 289-305.

[16] R. Sutherland, Basement geology and the tectonic development of the greater New Zealand region: an interpretation from regional magnetic data, Tectonophysics 308 (1999) 341-362.

[17] S. M. Greve, M. M. K. Savage, Modelling seismic anisotropy variations across the Hikurangi subduction margin, New Zealand, Earth \& Planet. Sc. Lett. 285 (2009) 16-26.

[18] R. Beavan, S. Ellis, L. Wallace, P. Denys, Kinematic constraints from GPS on oblique convergence of the Pacific and Australian Plates, central South Island, New Zealand, in: D. Okaya, T. Stern, F. Davey (Eds.), A continental Plate Boundary: tectonics at South Island, New Zealand Geophysical Monograph Series 175, American Geophysical Union, 2007, pp. 75-94.

[19] UNAVCO, Plate Boundary Observatory (PBO), component of the Earthscope MRE proposal, Tech. rep., UNAVCO (2002).

[20] M. M. Miller, M. Jackson, Plate Boundary Observatory (PBO), MREFC Close End of Project Report, Tech. rep., UNAVCO (2009).

[21] T. Melbourne, W. Szeliga, M. M. Miller, V. M. Santillan, Extent and duration 
of the 2003 Cascadia slow earthquake, Geophys. Res. Lett. 32 (L04301).

[22] B. Romanowicz, D. Neuhauser, B. Bogaert, D. Oppenheimer, Accessing northern California earthquake data via Internet, Eos Trans. Am. Geophys. Union 75 (23).

[23] M. H. Murray, D. Dreger, D. Neuhauser, D. Baxter, L. Gee, B. Romanowicz, Real-time geodesy, Seis. Res. Lett. 69 (145).

[24] N. Houlié, B. Romanowicz, Asymmetric deformation across the San Francisco Bay Area faults from GPS observations in Northern California, Phys. Earth Planet. Inter. 184 (3-4) (2011) 143-153.

[25] C. Bruyninx, M. Becker, G. Stangl, Regional Densification of the IGS in Europe Using the EUREF Permanent GPS Network (EPN), Phys. Chem. Earth 26 (68) (2001) 531-538.

[26] R. King, Y. Bock, Documentation of the GAMIT software, MIT/SIO (2006).

[27] Z. Altamimi, P. Sillard, C. Boucher, ITRF2000: A New Release of the International Terrestrial Reference Frame for Earth Science Applications, J. Geophys. Res. 107 (B10) (2002) 2114.

[28] A. Trota, N. Houlié, F. Sigmundsson, S. Jònsson, Deformations of the Furnas and Sete Cidade Volcanoes. Velocities and furt her investigations, Geophys. J. Int. $166(2)(2006) 952$.

[29] R. Walcott, Geodetic strains and large earthquakes in the axial tectonics belt of north island, new zealand, J. Geophys. Res. 83 (B9). 
[30] N. Cardozo, R. Allmendinger, Sspx: A program to compute strain from displacement/velocity data, Computers and Geosciences 35 (2009) 1343-1357.

[31] W. Menke, Geophysical Data Analysis: Discrete Inverse Theory, Academic Press, 1984.

[32] E. S. Cochran, SKS shear-wave splitting observations in the mantle beneath East Cape, New Zealand, Ph.D. thesis, Univ. of Leeds, Leeds (1999).

[33] E. R. Klosko, F. T. Wu, H. J. Anderson, D. Eberhardt-Phillips, T. V. McEvilly, E. Audoine, M. K. Savage, K. R. Gledhill, Upper mantle anisotropy in the New Zealand region, Geophys. Res. Lett. 26 (1999) 1497-1500.

[34] K. R. Gledhill, D. Gubbins, SKS splitting and the seismic anisotropy of the mantle beneath the Hikurangi subduction zone, New Zealand, Phys. Earth Planet. Inter. 95 (1996) 227-236.

[35] E. L. Audoine, M. Savage, K. R. Gledhill, Anisotropic structure under a backarc spreading region, the Taupo Volcanic Zone, New Zealand, J. Geophys. Res. 109.

[36] M. Duclos, M. K. Savage, A. Tommasi, K. R. K. R. Gledhill, Mantle Tectonics beneath New Zealand Inferred from SKS Splitting and Petrophysics, Geophys. J. Int. 163 (2005) 760-774.

[37] S. J. Bourne, P. England, B. Parsons, The motion of crustal blocks driven by flow of the lower lithosphere and implications for slip rates of continental strikeslip faults, Nature 391.

[38] C. Kreemer, W. Holt, A. Haines, An integrated global model of present-day 
plate motions and plate boundary deformation, Geophys. J. Int. 154 (2003) 8-34.

[39] R. J. Norris, P. Koons, C. A.F., The obliquely convergent plate boundary in the South Island of New Zealand; implications for ancient collision zones, J. Struct. Geology 12 (5-6) (1990) 715-725.

[40] J. Beavan, M. Moore, C. Pearson, M. Henderson, B. Parsons, S. Bourne, P. England, D. Walcott, G. Graeme Blick, D. Desmond Darby, K. Hodgkinson, Crustal deformation during 1994-1998 due to oblique continental collision in the central Southern Alps, New Zealand, and implications for seismic potential of the Alpine Fault, J. Geophys. Res. 104 (B11) (1999) 25233-25255.

[41] J. Beavan, D. Matheson, P. Denys, M. Denham, T. Herring, B. Hager, P. P. Molnar, A vertical deformation profile across the Southern Alps, New Zealand, from 3.5 years of continuous GPS data, in: The state of GPS vertical positioning precision: separation of earth processes by space geodesy, Cahiers de Centre Europeen de Geodynamique et seismologie, 2004.

[42] J. Beavan, P. Denys, M. Denham, B. Hager, T. Herring, P. Molnar, Distribution of present day vertical deformation across the Southern Alps, New Zealand, from 10 years of GPS data, Geophys. Res. Lett. 37 (L16305).

[43] P. Wessel, W. Smith, Free software helps map and display data, Eos Trans. Am. Geophys. Union 72 (441) (1991) 445-446.

[44] B. Hayward, H. Grenfell, A. Sabaa, J. Jon Kay, R. Daymond-King, U. Cochran, Holocene subsidence at the transition between strike-slip and subduction on 
the Pacific-Australian plate boundary, Marlborough Sounds, New Zealand, Quaternary Sci. Rev. 29 (2010) 648-661.

[45] C. Cotton, The Tuamarina Valley: A Note on the Quaternary History of the Marlborough Sounds District, Trans. New Zealand Inst. 45 (1913) 316-322.

[46] R. I. Walcott, Geodetic strain and the deformational history of the North Island of New Zealand during the late Cenozoic, Phil. Trans. R.Soc. Lond. A 321 (1987) $163-181$.

[47] A. Pulford, T. Stern, Pliocene exhumation and landscape evolution of central North Island, New Zealand: the role of the upper mantle, J. Geophys. Res. 109.

[48] J. R. Pelton, R. Smith, Recent Crustal uplift in Yellowstone National Park, Science 206 (4423) (1979) 1179-1182.

[49] C. A. Cotton, Skeleton Islands of New Zealand and elsewhere, in: B. Collins (Ed.), Bold Coasts, A.H. and A.W. Reed, Wellington, 1974, pp. 306-323.

[50] J. G. Begg, C. Mazengarb, The geology of the Wellington Area, scale 1:50,000, IGNS Ltd., Lower Hutt, Lower Hutt. .

[51] R. Van Dissen, R. Yeats, Hope fault, Jordan thrust, and uplift of the seaward Kaikoura Range, New Zealand, Geology 19 (1991) 393-396.

[52] R. Walcott, Modes of oblique compression: Late Cenozoic tectonics of the South Island of New Zealand, Rev. Geophys. 36 (1).

[53] T. A. Stern, P. Molnar, D. Okaya, D. Eberhart-Phillips, Teleseismic P-wave delays and modes of shortening the mantle beneath the South Island, New Zealand, J. Geophys. Res. 105 (2000) 21,615-621,631. 
[54] S. Lamb, Shear stresses on megathrusts: Implications for mountain building behind subduction zones, J. Geophys. Res. 111 (B07401).

[55] T. Stern, A. Benson, Wide-angle seismic imaging beneath an andesitic arc: Central North Island, New Zealand, J. Geophys. Res. 116 (B09308) (2011) 26.

[56] M. Reyners, D. Eberhart-Phillips, G. Stuart, Y. Nishimura, Imaging subduction from the trench to $300 \mathrm{~km}$ depth beneath the central North Island, New Zealand, with Vp and Vp/Vs, Geophys. J. Int. 165 (2006) 565-583.

[57] A. M. Seward, C. M. Henderson, E. G. C. Smith, Models of upper mantle beneath the Central North Island, New Zealand, from speeds and anisotropy of sub-horizontal P-waves (Pn), J. Geophys. Res. 114 (B01301).

[58] T. Stern, F. Davey, A seismic investigation of the crustal and upper mantle structure within the central volcanic region of New-Zeland, New Zeal. J. Geol. Geop. 30 (3) (1987) 217-231.

[59] H. M. Bibby, T. G. Caldwell, F. J. Davey, T. H. Webb, Geophysical evidence on the structure of the Taupo Volcanic Zone and its hydrothermal circulation, J. Volcanol. Geotherm. Res. 68 (1995) 29-58.

[60] S. J. Bourne, T. Árnadóttir, J. Beavan, D. J. Darby, P. England, B. Parsons, R. I. Walcott, P. P. R. Wood, Crustal deformation of the marlborough fault zone in the south island of new zealand: Geodetic constraints over the interval 1982-1994, J. Geophys. Res. 103 (B12) (1998) 30,147-30,165.

[61] A. Tommasi, B. Tikoff, A. Vauchez, Upper mantle tectonics: three-dimensional deformation, olivine crystallographic fabrics and seismic properties, Earth \& 
Planet. Sc. Lett. 168 (1999) 173-186.

[62] S. Karalliyadda, M. Savage, T. Stern, Seismic Anisotropy in Lithospheric Depths of the Plate Boundary Zone: Inferences from Shear-wave Splitting of Local S Phases, Eos Trans. Am. Geophys. Union S41A-2176, (2011).

[63] B. D. Leitner, D. Eberhart-Phillips, H. Anderson, J. Nabelek, A focused look at the Alpine fault, New Zealand: Seismicity, focal mechanisms, and stress observations, J. Geophys. Res. 106 (2001) 2193-2220.

[64] N. Balfour, M. Savage, J. Townend, Stress and crustal anisotropy in Malborough, New Zealand: evidence for low fault strength and structurecontrolled anisotropy, Geophys. J. Int. 163 (2005) 1073-1086.

[65] C. Boese, J. Townend, E. Smith, T. Stern, Microseismicity of the Alpine fault zone: mechanisms of faulting and the state of stress in the central south Islland, New Zealand, J. Geophys. Res. .

[66] J. L. Hardebeck, A. Michael, Stress orientations at intermediate angles to the San Andreas Fault, California, J. Geophys. Res. 109 (B11303).

[67] T. Stern, S. Kleffmann, D. Okaya, M. Scherwath, S. Bannister, Low seismic wave-speeds and enhanced fluid pressure beneath the Southern Alps, New Zealand, Geology 29 (2001) 679-682.

[68] D. Eberhart-Phillips, G. Bannister, 3-d imaging of marlborough, new zealand, subducted plate and strike-slip fault systems, Geophys. J. Int. 182 (1) (2010) 73-96.

[69] T. Little, M. Savage, T. Basil, Relationship between crustal finite strain and 
seismic anisotropy in the mantle, Pacific-Australia plate boundary zone, South Island, New Zealand, Geophys. J. Int. 151 (1) (2002) 106-116.

[70] D. Dowrick, Damage and intensities in the magnitude 7.81931 Hawke's Bay, New Zealand, Earthquake, Bulletin of the New Zealand National Society for Earthquake Engineering 31 (3) (1998) 139-163.

[71] L. Wallace, J. Beavan, Diverse slow slip behavior at the hikurangi subduction margin, new zealand, J. Geophys. Res. 115 (B12402).

[72] R. Twiss, E. Moores, Structural Geology, 2nd edition, W.H. Freeman, 2006. 
Fig. 1. GEONET network velocity field with respect to the site New Plymouth (NPLY). Note the relative lack of activity in western South and North Islands. The station GUNR is a new station introduced in 2009 and has limited data base. We did not use data from this station in creating the uplift or strain maps.

Fig. 2. a) Surface uplift rate map of New Zealand. Here we have extrapolated between stations onto a $\sim 50 \mathrm{~km}$ grid with bicubic splines then contoured with GMT [43. Two main areas can be distinguished where there is uplift higher than uncertainties. See text for discussion.

Fig. 3. Same as Figure 2 without interpolation.

Fig. 4. Strain rate components computed from the GEONET velocity field.

Fig. 5. a) Theoretical vertical strain rate computed from the principal strain rate components $\left(\dot{\varepsilon_{1}}\right.$ and $\left.\dot{\varepsilon_{2}}\right)$ assuming the material is incompressible. b) Expected rate of the base of the crust $V$. When $V$ is negative the crust is thickened. c) Expected uplift deduced of the theoretical strain rate map. The peak-to-peak amplitude of the ground motion does not exceed $2 \mathrm{~mm} / \mathrm{yr}$. We detail in the text the assumptions to reach this result.

Fig. 6. Left: Comparison of the orientations of the axis of shortening from GPS (red) with the fast axis of shear wave splitting (blue) and with the compression axis from geodetic survey ([2], black). We explain in detail the implications of these observations in the text. We find that while the geodetic and present day shortening directions agree, some transient deformation related to the 1931 Napier earthquake [70], is visible along the east coast of North Island. Right: Comparison of the orientations of the planes of maximum shear from GPS (green) with the fast axis of shear wave splitting (blue).

Fig. 7. Same as Figure 5.a for GPS campaigns published by [71].

Fig. 8. Left: $\theta$ angle values between orientations of the axis of compression from GPS and the SKS orientations and with the compression axis from geodetic survey (black). Right: Angles between the GPS compression strain rate axis and the strike of the faults. We substracted the strike of the fault to the shortening directions.More details in the text. The values have been interpolated using splines [43] on a $0.5 \times 0.5$ grid of points.

Fig. 9. Cartoon showing how an orginal spherical reference body can be deformed by simple and pure shear. For simple shear there is numerical relationship between the width of shear zone, the amount of offset across the zone and the angle $(\theta)$ between the maximum extension and the direction of shear. In pure shear the angle $\theta$ is $=0$. Combinations of pure and simple shear can produce variable SKS directions as shown by [61]. Figure after [72] 
Fig. 10. Distribution of the values of $\theta$ in zones 2 and 3 . We note a shift in the average value of $\theta$ of about 40 degrees. The values of $\theta$ are more scattered in zone 2. This suggests that some areas have higher values of $\theta$ than others.

Fig. 11. Distribution of the values of $\alpha$ for areas south (south island) and north (north island) of the latitude S41. We find that the distribution for South Island shows two peaks that we can associate with the zones 2 and 3 described using the difference the SKS fast axis and GPS compression directions. 


\begin{tabular}{|c|c|c|c|c|c|c|}
\hline Site & Lon. & Lat. & Ve & Vn & $\mathrm{Se}$ & Sn \\
\hline & (deg.) & (deg.) & $\mathrm{mm} / \mathrm{yr}$ & $\mathrm{mm} / \mathrm{yr}$ & $\mathrm{mm} / \mathrm{yr}$ & $\mathrm{mm} / \mathrm{yr}$ \\
\hline AUCK & 174.83 & -36.60 & 3.7 & 38.5 & 0.2 & 0.2 \\
\hline AUKT & 174.77 & -36.84 & -1.4 & 31.5 & 2.0 & 2.0 \\
\hline BLUF & 168.29 & -46.59 & -36.9 & 34.5 & 0.5 & 0.5 \\
\hline CAST & 176.20 & -40.91 & -29.2 & 27.4 & 0.6 & 0.6 \\
\hline CMBL & 174.21 & -41.75 & -25.7 & 32.0 & 0.5 & 0.5 \\
\hline CORM & 175.75 & -36.87 & 3.5 & 38.3 & 0.5 & 0.5 \\
\hline DUND & 170.60 & -45.88 & -37.8 & 30.4 & 0.6 & 0.6 \\
\hline DURV & 173.92 & -40.80 & -6.6 & 38.6 & 0.6 & 0.6 \\
\hline GISB & 177.89 & -38.64 & -1.9 & 19.8 & 0.5 & 0.5 \\
\hline GLDB & 172.53 & -40.83 & -2.6 & 42.2 & 0.6 & 0.6 \\
\hline GUNR & 170.39 & -43.39 & -20.5 & 12.6 & 2.0 & 2.0 \\
\hline \multicolumn{7}{|c|}{ Continued on next page } \\
\hline
\end{tabular}


series Table 1 - continued from previous page

\begin{tabular}{|c|c|c|c|c|c|c|}
\hline HAAS & 168.79 & -44.07 & -15.3 & 40.1 & 0.6 & 0.6 \\
\hline HAMT & 175.11 & -37.81 & 1.2 & 38.9 & 0.5 & 0.5 \\
\hline HAST & 176.73 & -39.62 & -6.4 & 24.4 & 0.5 & 0.5 \\
\hline HIKB & 178.30 & -37.56 & 5.7 & 19.4 & 0.5 & 0.5 \\
\hline HOKI & 170.98 & -42.71 & -4.7 & 42.9 & 0.4 & 0.4 \\
\hline KTIA & 173.27 & -35.07 & 3.5 & 40.7 & 2.0 & 2.0 \\
\hline KUTA & 177.07 & -39.17 & -1.5 & 15.7 & 2.0 & 2.0 \\
\hline LEVN & 175.24 & -40.59 & -23.9 & 31.1 & 2.0 & 2.0 \\
\hline LEXA & 169.31 & -45.23 & -37.0 & 31.6 & 0.6 & 0.6 \\
\hline LKTA & 172.27 & -42.78 & -24.3 & 32.9 & 0.5 & 0.5 \\
\hline MAHA & 173.79 & -41.29 & -19.5 & 40.4 & 2.0 & 2.0 \\
\hline MAHO & 174.85 & -38.51 & 0.6 & 39.1 & 0.6 & 0.6 \\
\hline
\end{tabular}


series Table 1 - continued from previous page

\begin{tabular}{|c|c|c|c|c|c|c|}
\hline MAVL & 168.12 & -45.37 & -44.6 & 33.9 & 0.6 & 0.6 \\
\hline MQZG & 172.65 & -43.70 & -35.5 & 31.0 & 0.4 & 0.4 \\
\hline MTJO & 170.46 & -43.99 & -29.6 & 32.5 & 0.4 & 0.4 \\
\hline NLSN & 173.43 & -41.18 & -6.5 & 40.4 & 0.6 & 0.6 \\
\hline NPLY & 174.12 & -39.18 & -0.8 & 39.5 & 0.5 & 0.5 \\
\hline OKOH & 174.06 & -41.02 & -20.0 & 36.4 & 2.0 & 2.0 \\
\hline TAUP & 176.08 & -38.74 & 5.9 & 32.2 & 0.5 & 0.5 \\
\hline TORY & 174.28 & -41.19 & -12.5 & 37.8 & 0.6 & 0.6 \\
\hline TRNG & 176.26 & -37.73 & 3.5 & 36.9 & 0.5 & 0.5 \\
\hline WAIM & 170.92 & -44.66 & -35.3 & 30.2 & 0.6 & 0.6 \\
\hline WANG & 174.82 & -39.79 & -3.4 & 38.0 & 0.5 & 0.5 \\
\hline WARK & 174.66 & -36.43 & -2.0 & 39.6 & 2.0 & 2.0 \\
\hline
\end{tabular}


series Table 1 - continued from previous page

$\begin{array}{ccccccc}\text { WEST } & 171.81 & -41.74 & -3.5 & 41.8 & 0.6 & 0.6 \\ \text { WGTN } & 174.81 & -41.32 & -25.5 & 32.5 & 0.3 & 0.3 \\ & & & & & & \\ \text { WITH } & 173.98 & -41.56 & -23.8 & 35.6 & 2.0 & 2.0\end{array}$

Table 1: GEONET velocities in ITRF2000. Velocity field is plotted with respect to New Plymouth (NPLY) on Figure 1 


\begin{tabular}{|c|c|c|c|c|c|}
\hline Site & $\begin{array}{l}\text { Lat. } \\
\text { deg. }\end{array}$ & $\begin{array}{l}\text { Lon } \\
\text { deg. }\end{array}$ & $\begin{array}{c}V_{u p} \\
(\mathrm{~mm} / \mathrm{yr})\end{array}$ & $\begin{array}{c}V_{u p} / \mathrm{CAST} \\
(\mathrm{mm} / \mathrm{yr})\end{array}$ & $\begin{array}{c}\sigma_{u p} \\
(\mathrm{~mm} / \mathrm{yr})\end{array}$ \\
\hline AUCK & -36.60 & 174.83 & 8.5 & 2.0 & 2.2 \\
\hline BLUF & -46.58 & 168.29 & 9.6 & 3.1 & 2.5 \\
\hline CAST & -40.90 & 176.20 & 6.5 & 0.0 & 3.1 \\
\hline CMBL & -41.74 & 174.21 & 10.4 & 3.9 & 2.4 \\
\hline CORM & -36.86 & 175.74 & 8.9 & 2.4 & 2.4 \\
\hline DUND & -45.88 & 170.59 & 9.1 & 2.6 & 2.8 \\
\hline DURV & -40.80 & 173.92 & 8.0 & 1.5 & 2.7 \\
\hline GISB & -38.63 & 177.88 & 7.9 & 1.4 & 2.3 \\
\hline HAAS & -44.07 & 168.78 & 11.0 & 4.5 & 2.5 \\
\hline HAMT & -37.80 & 175.10 & 8.6 & 2.1 & 2.4 \\
\hline HIKB & -37.56 & 178.30 & 8.9 & 2.4 & 2.4 \\
\hline HOKI & -42.71 & 170.98 & 11.6 & 5.0 & 2.2 \\
\hline KTIA & -35.06 & 173.27 & 10.4 & 4.0 & 4.2 \\
\hline LEVN & -40.58 & 175.24 & 12.6 & 6.1 & 6.4 \\
\hline LEXA & -45.23 & 169.30 & 8.7 & 2.2 & 2.5 \\
\hline MAVL & -45.36 & 168.11 & 9.1 & 2.6 & 2.6 \\
\hline MQZG & -43.70 & 172.65 & 9.7 & 3.2 & 2.2 \\
\hline MTJO & -43.98 & 170.46 & 9.5 & 3.0 & 2.2 \\
\hline NLSN & -41.18 & 173.43 & 8.4 & 1.9 & 2.5 \\
\hline NPLY & -39.18 & 174.11 & 8.1 & 1.6 & 2.4 \\
\hline TAUP & -38.74 & 176.08 & 13.3 & 6.8 & 2.3 \\
\hline TORY & -41.19 & 174.28 & 10.3 & 3.8 & 2.7 \\
\hline TRNG & -37.72 & 176.26 & 10.2 & 3.7 & 2.4 \\
\hline WAIM & -44.65 & 170.92 & 9.1 & 2.6 & 2.6 \\
\hline WANG & -39.78 & 174.82 & 9.2 & 2.7 & 2.4 \\
\hline WEST & -41.74 & 171.80 & 7.8 & 1.2 & 2.6 \\
\hline WGTN & -41.32 & 174.80 & 8.4 & 1.9 & 2.2 \\
\hline
\end{tabular}

Table 2

GEONET network vertical rates in the ITRF2000 and with respect to the site CAST 


\section{Highlights}

We compute the strain rate in New Zealand from the GEONET GPS velocity field

We compare the axis of compression from the GPS velocity field with the fast axis of SKS splitting

We show that, in some areas, mantle deformation and present-day crustal tectonic strongly related 


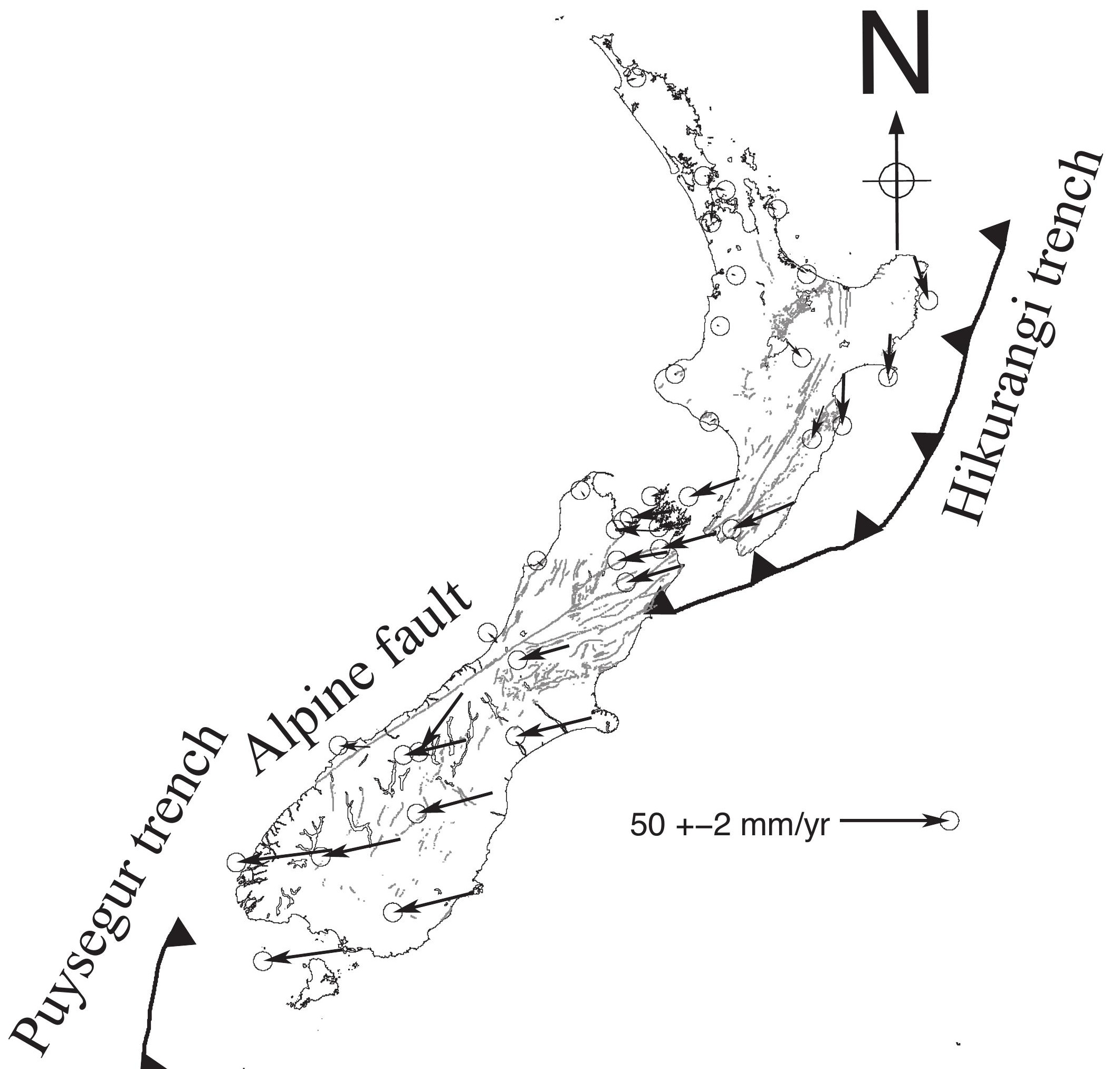


Click here to download Figure: F2-NZ.vert.eps

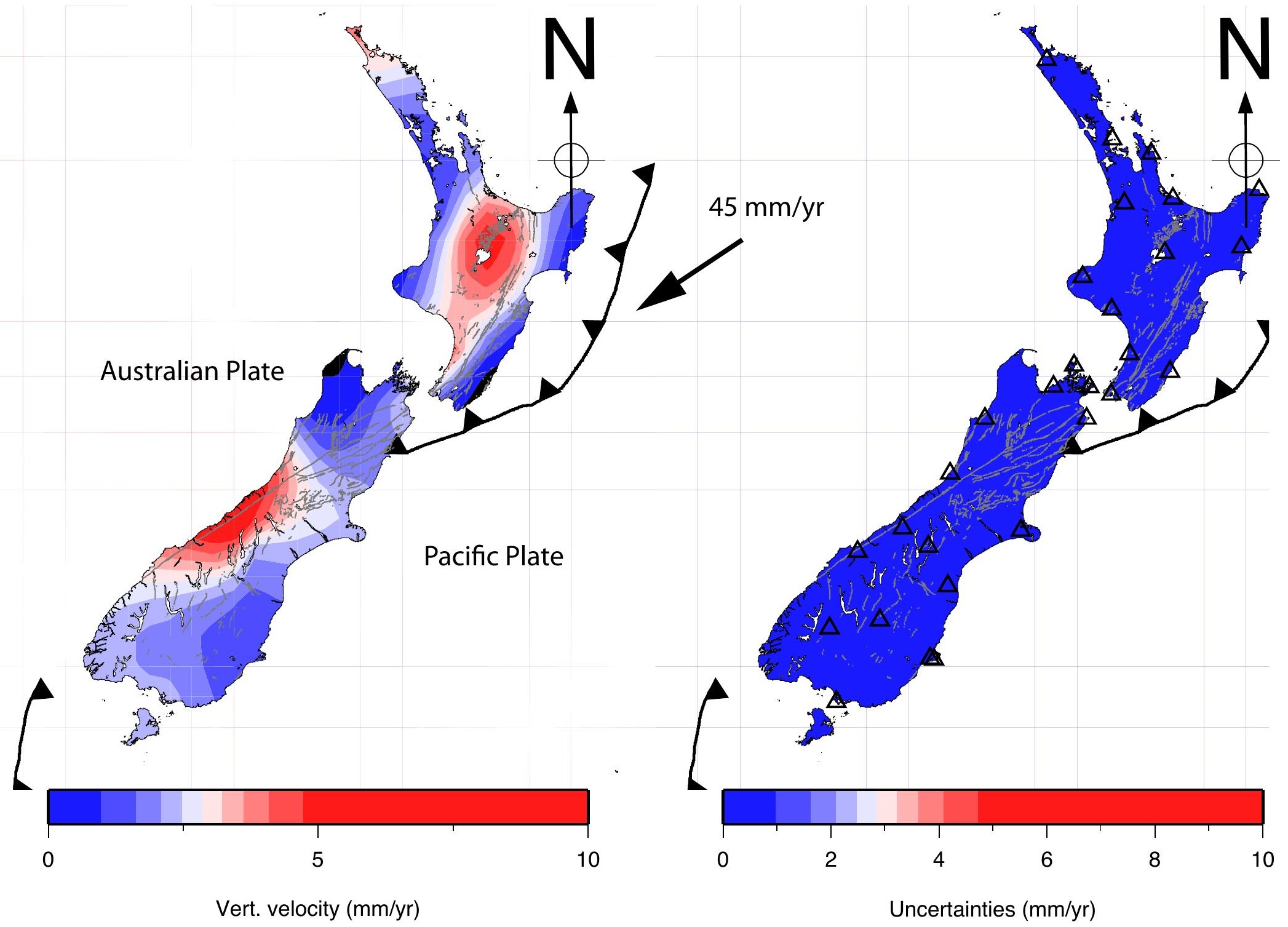



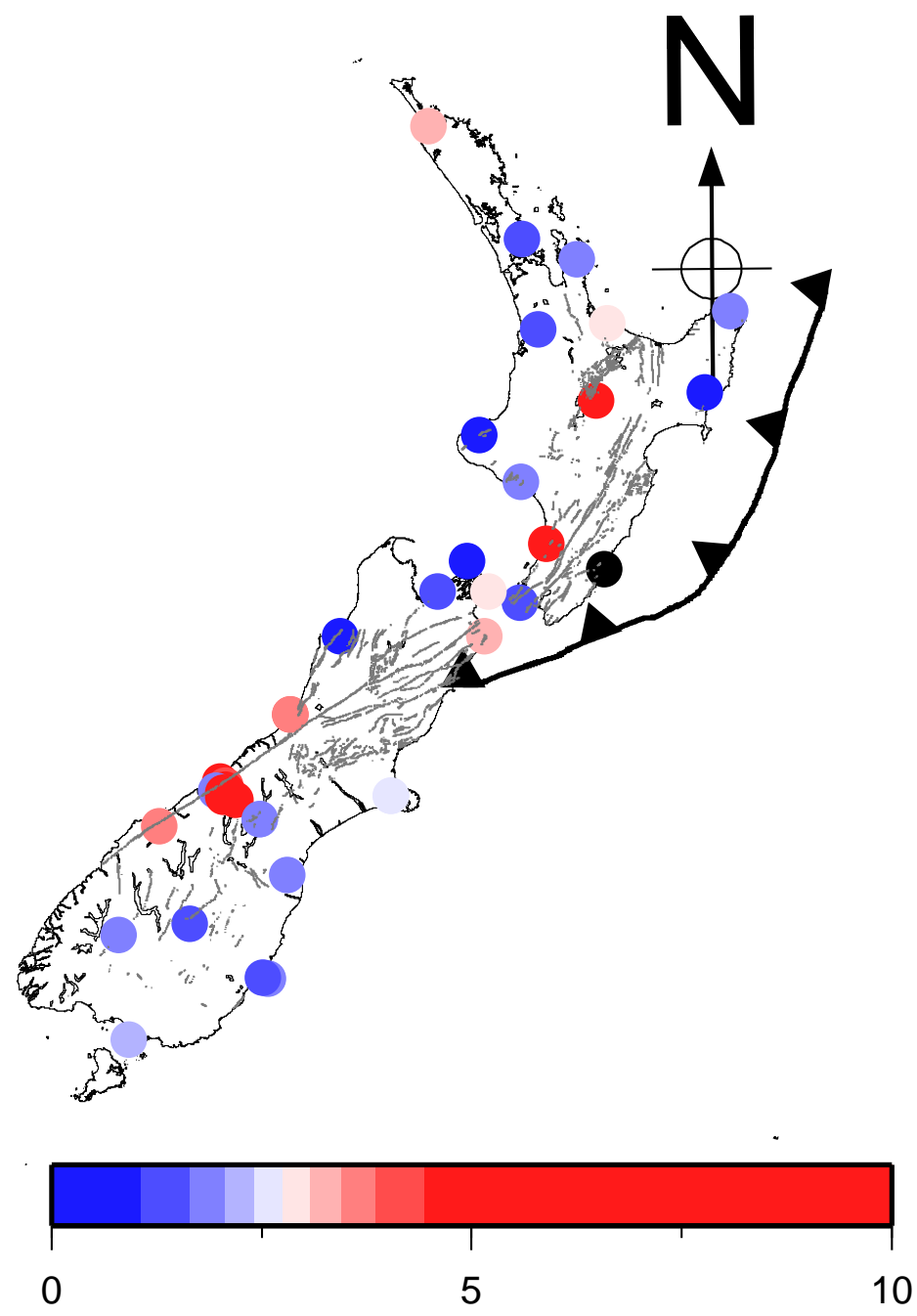

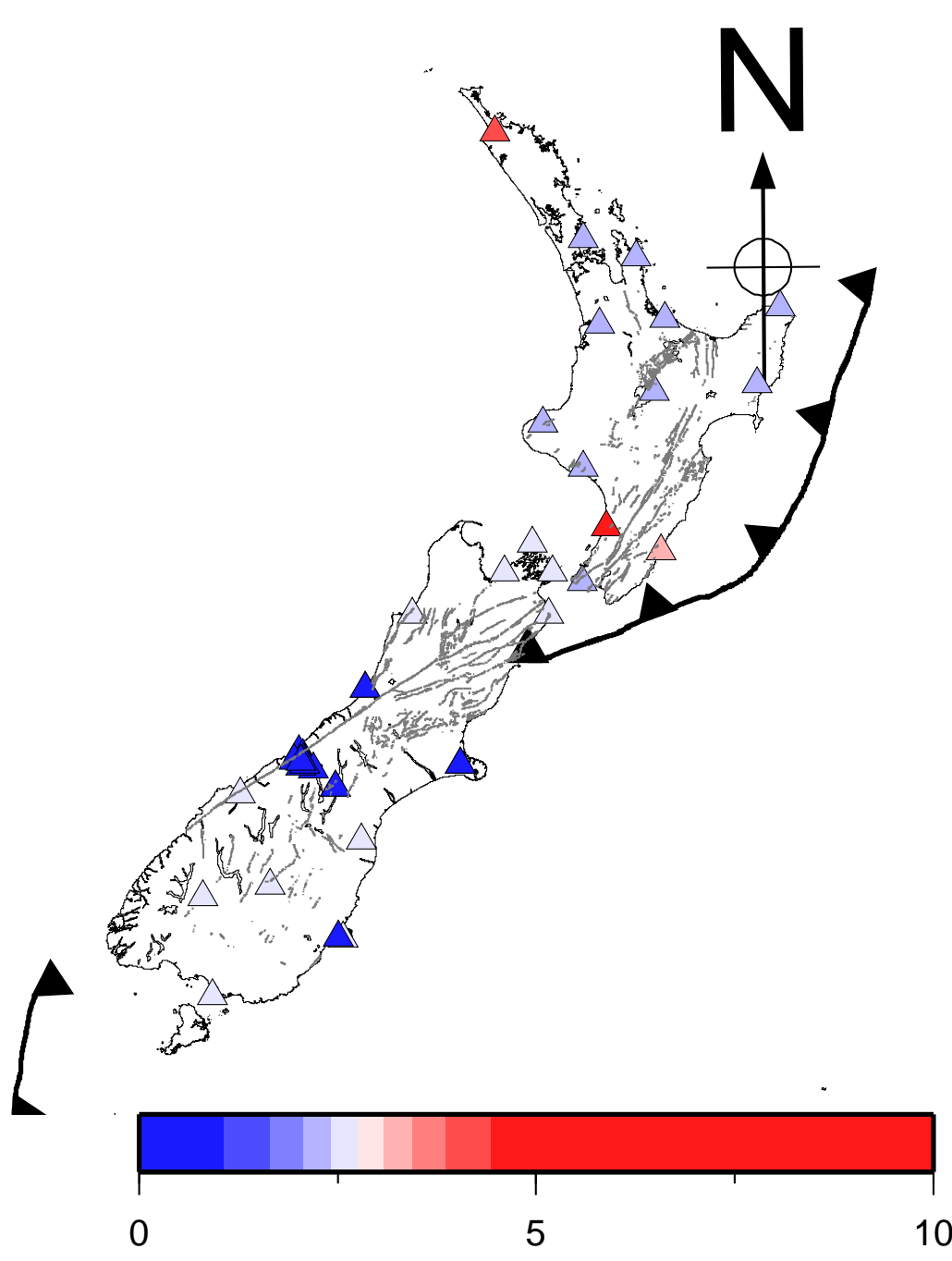

Uncertainties (mm/yr) 
Figure 4

Click here to download Figure: F4-geonet.velo.eps
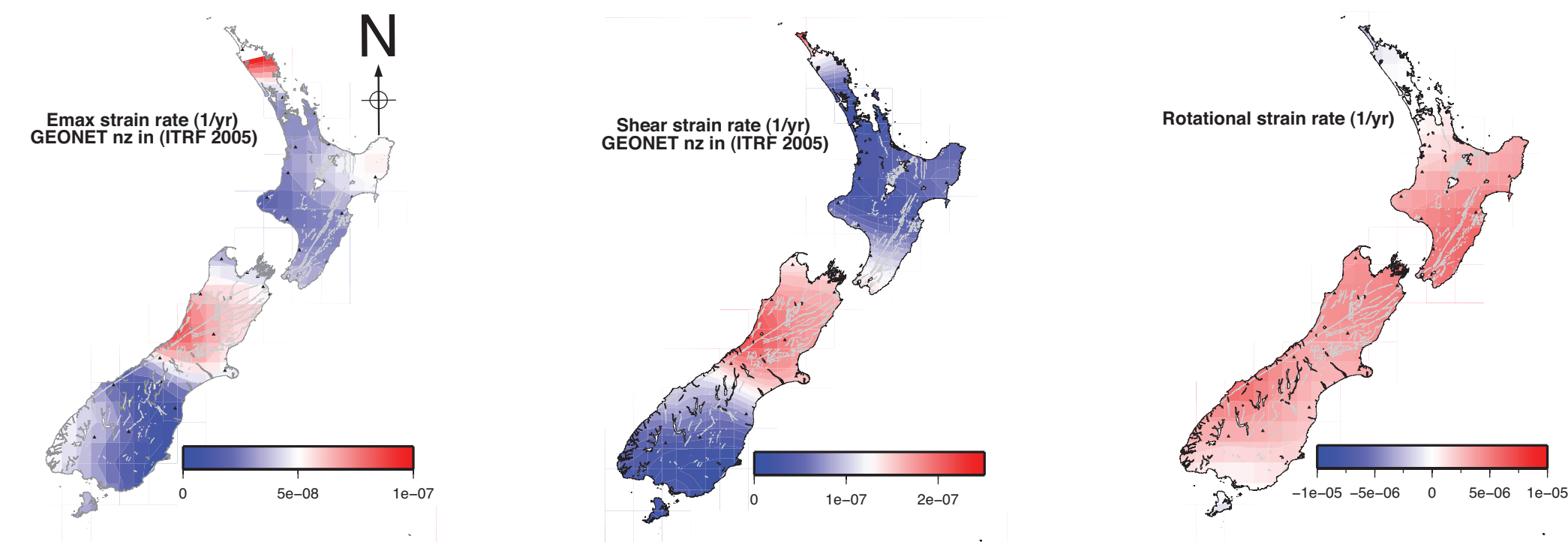
Figure 5
Click here to download Figure: F5-NZ.root.eps

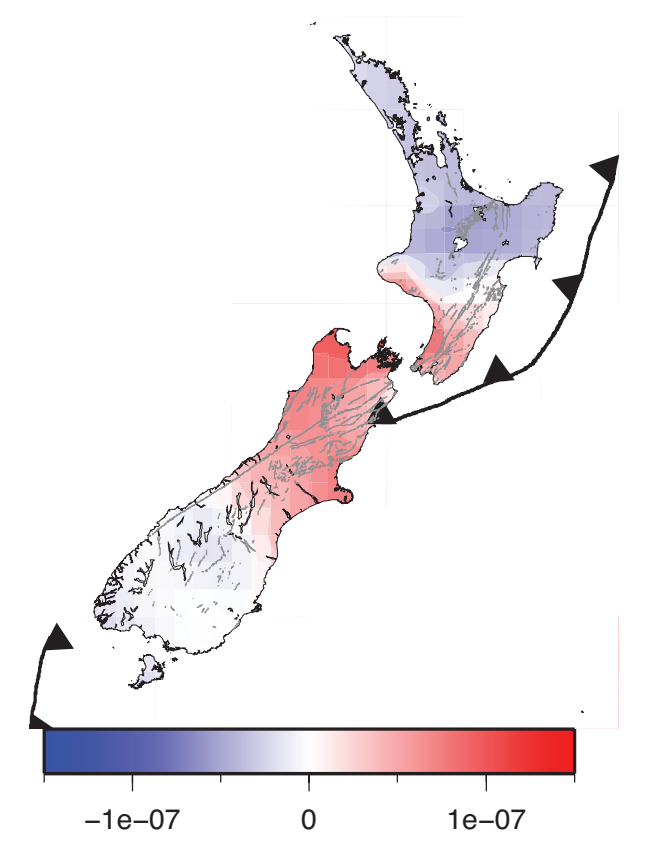

Vertical Strain rate (/yr)
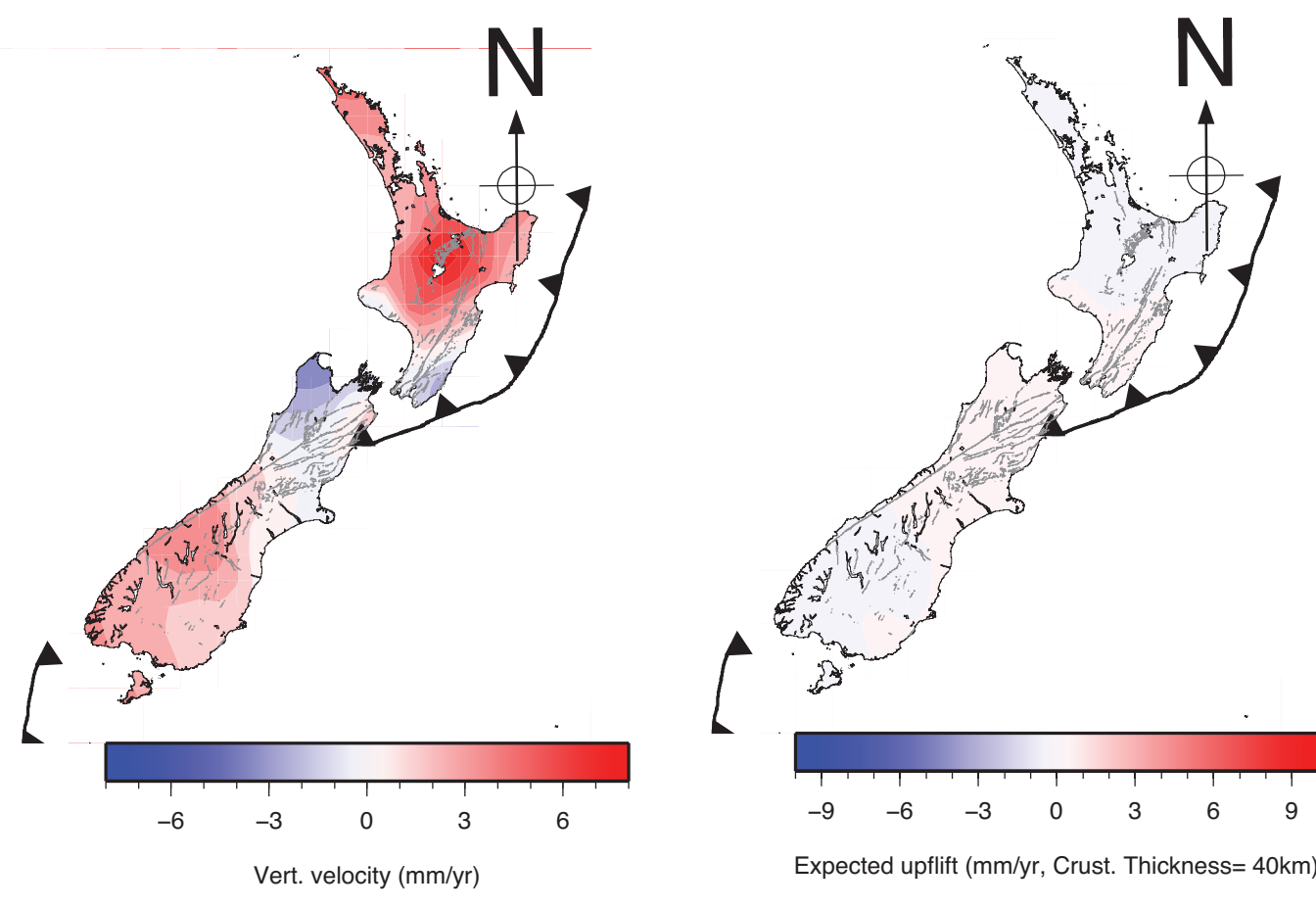

Expected upflift $(\mathrm{mm} / \mathrm{yr}$, Crust. Thickness $=40 \mathrm{~km})$ 
Click here to download Figure: F6-sks.geonet.eps
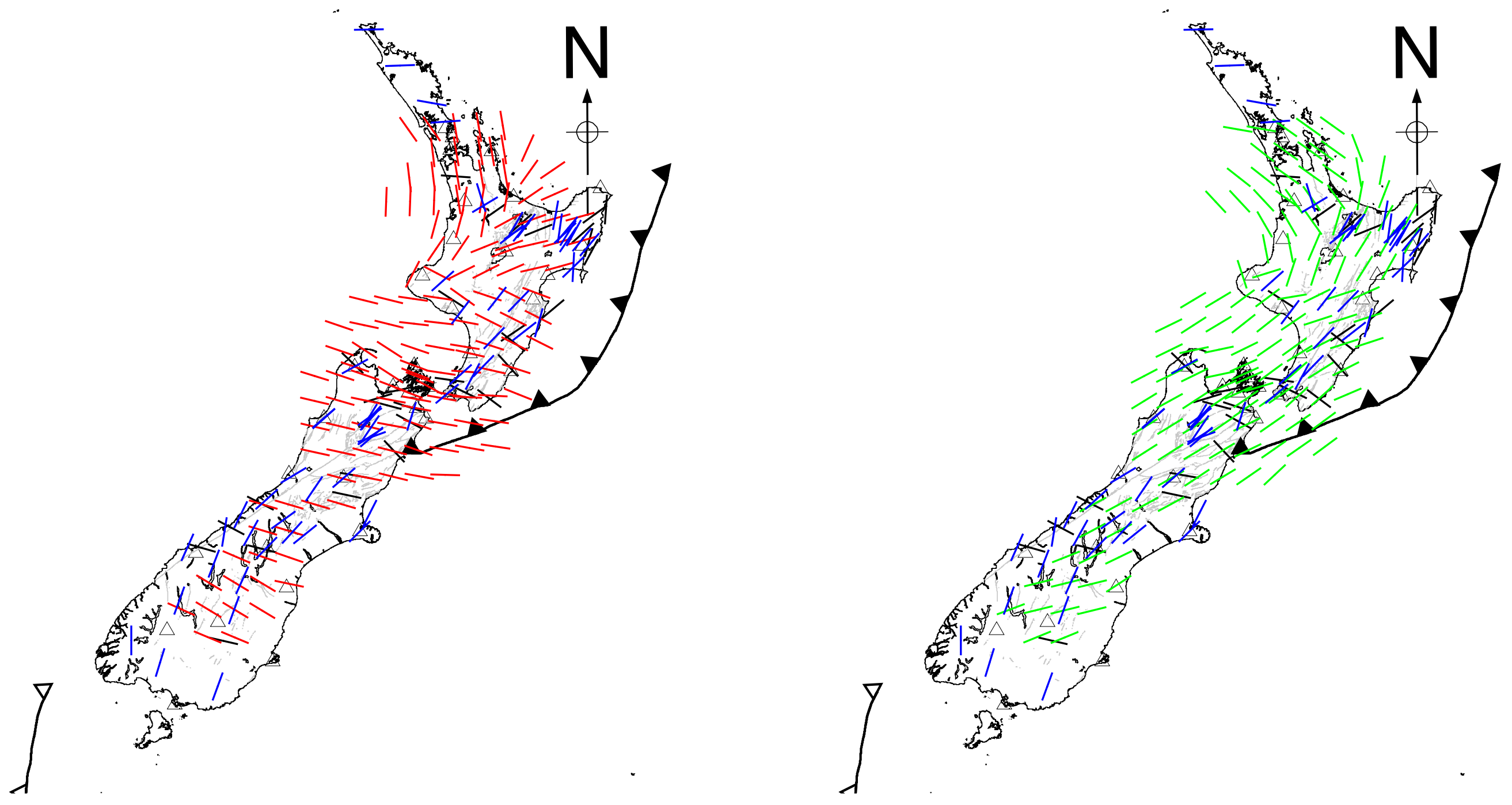


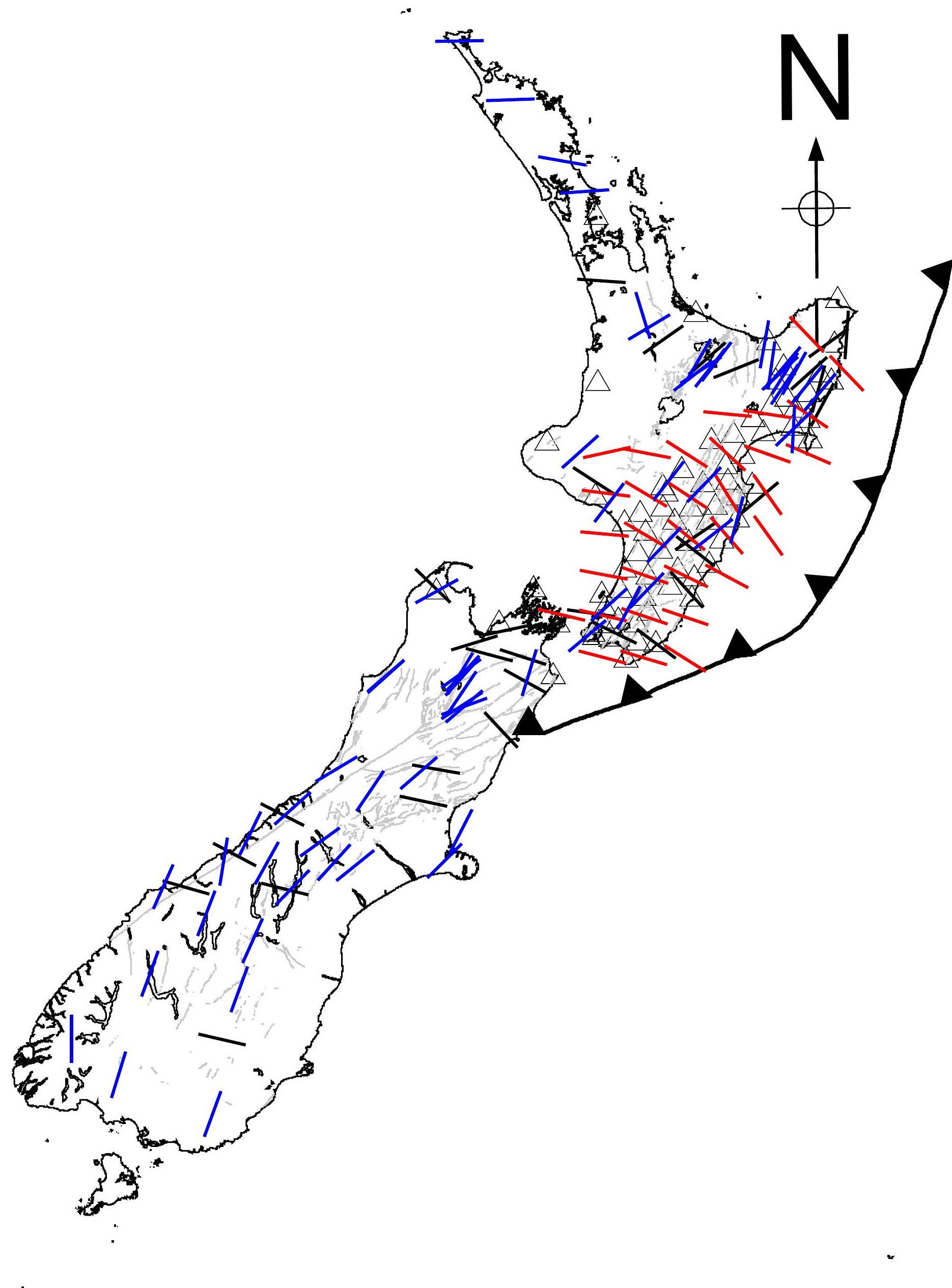



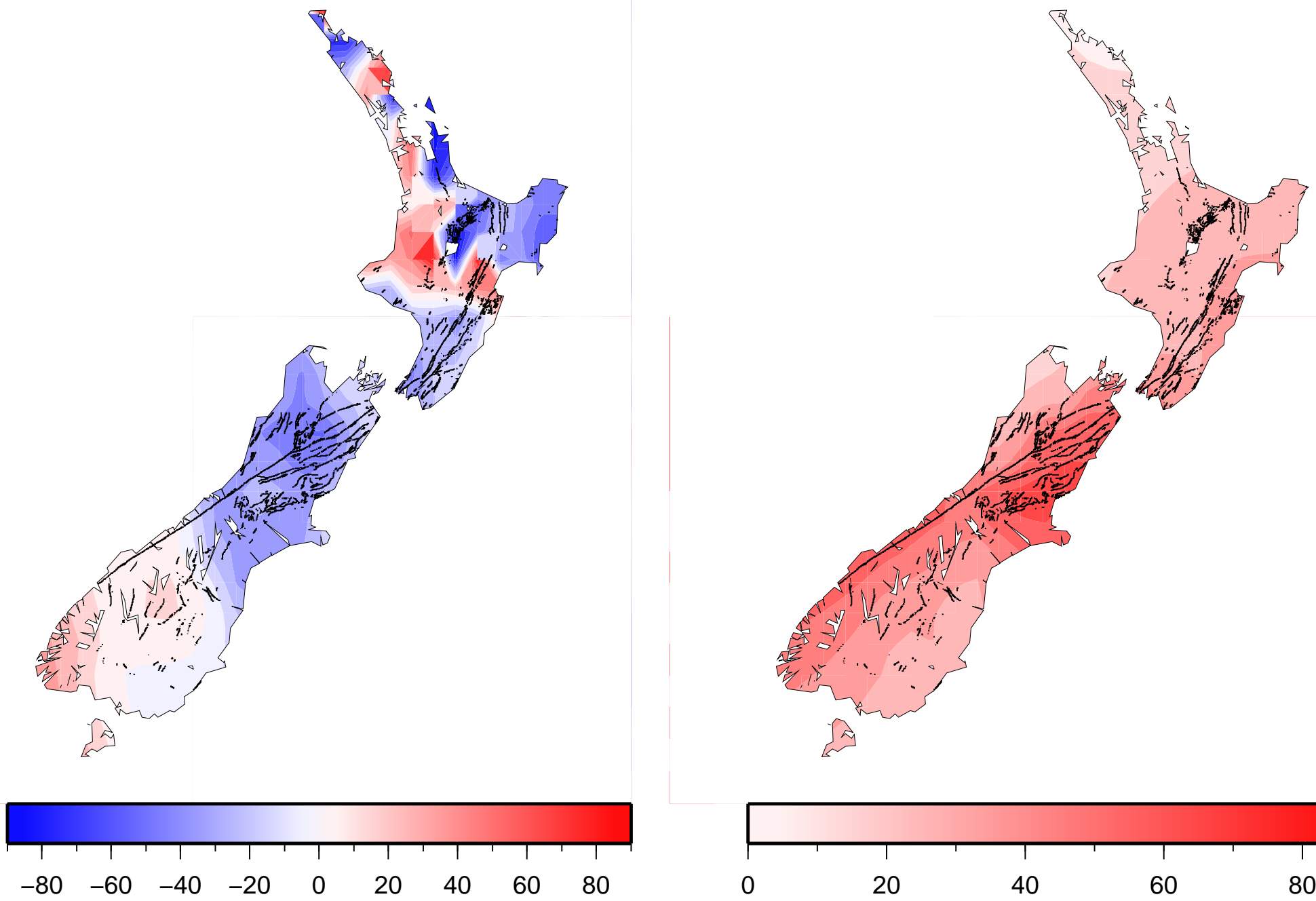

Theta (deg.)

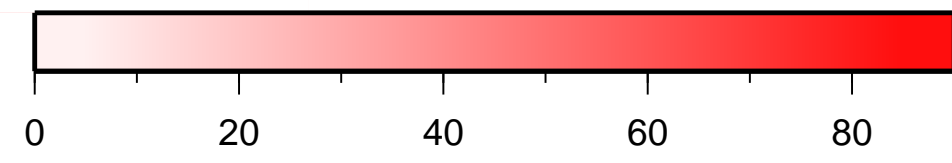

Alpha (deg.) 
Click here to download Figure: F9-

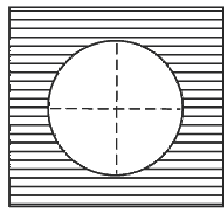

No Deformation
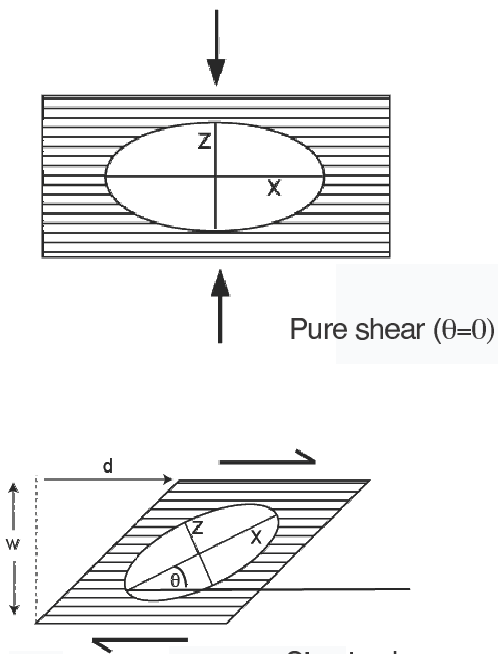

Simple shear $\tan (2 \theta)=2 \mathrm{w} / \mathrm{d}$ 
ङ 20

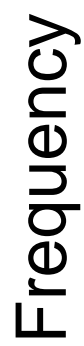

15
10

$10-1$
$5-1$

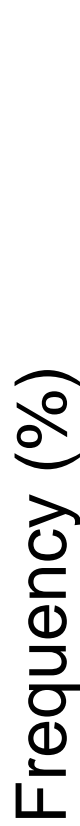

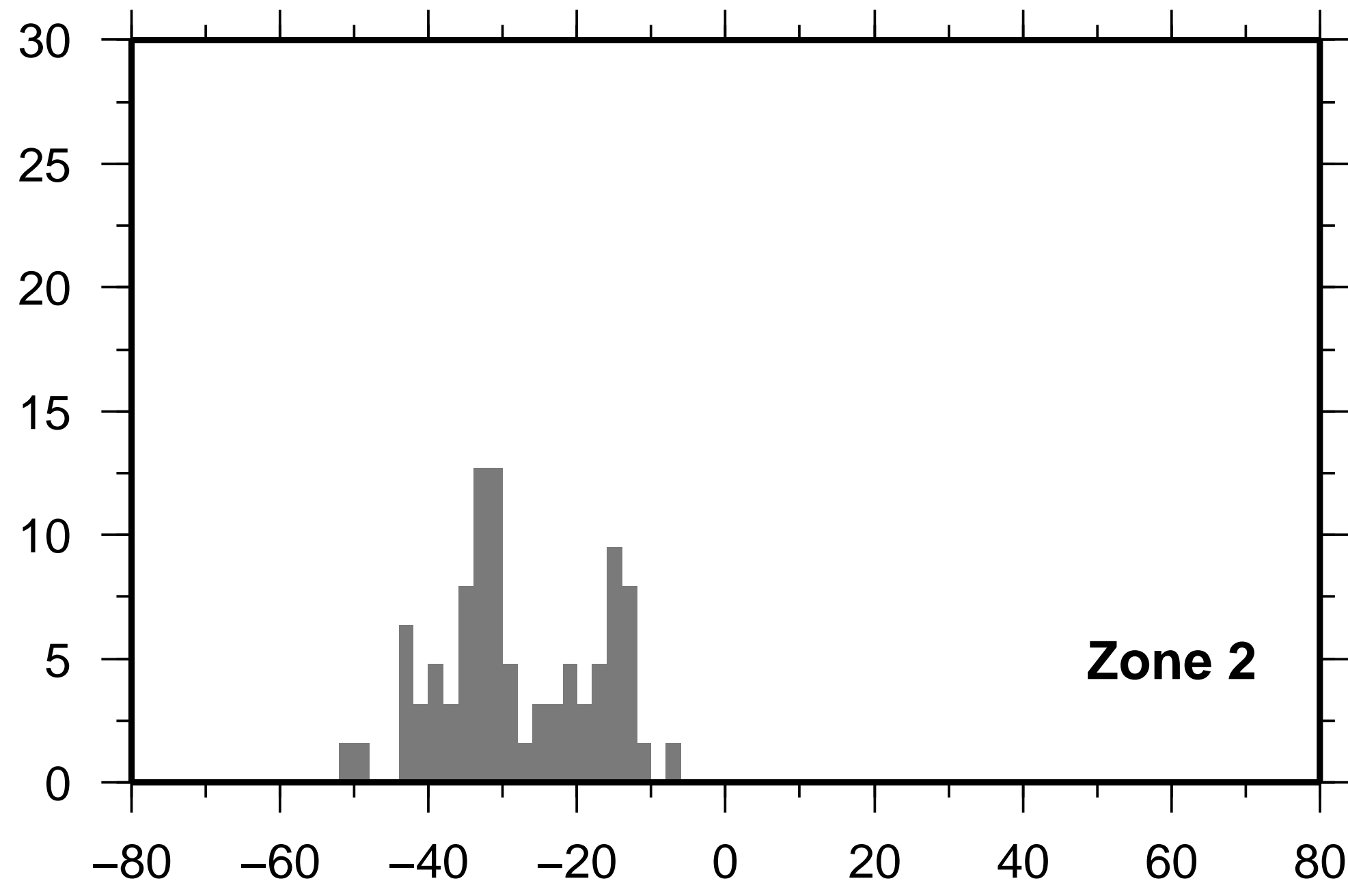

Alpha 
$\begin{aligned} & \text { Figure } 11 \\ & \text { Click here } 15 \text { down|pad Figure: F11-stat.alpha.eps }\end{aligned}$

\section{South of S41}

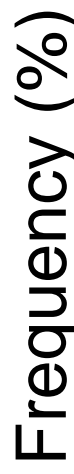

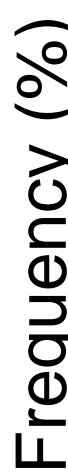
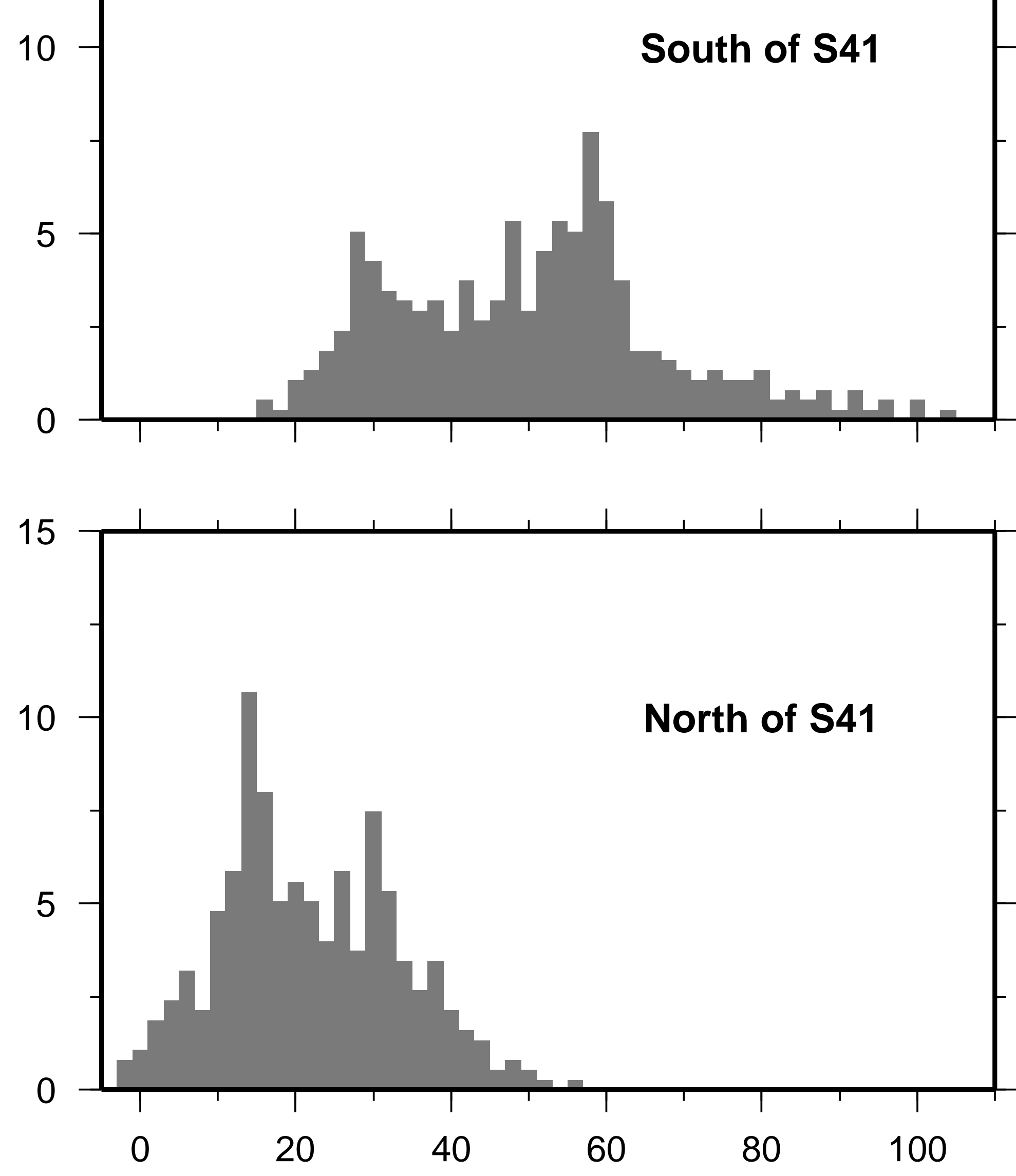

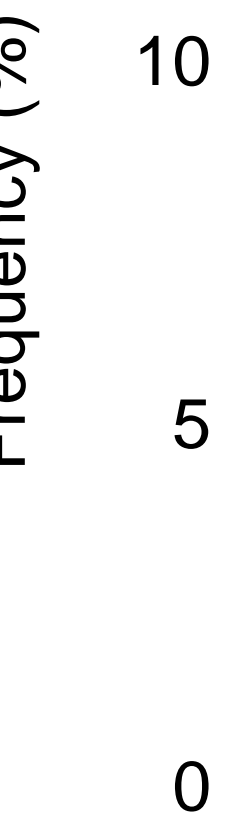

0

20

40

60

80

100

\section{Alpha}

